\title{
BALLISTIC MISSILE DEFENCE AND THE CHANGING NATURE OF DETERRENCE: THE US REBALANCE AND CHINA'S NUCLEAR STRATEGY
}

\author{
James Dwyer*
}

As the US continues its rebalance to the Asia-Pacific, more attention is being paid to the role of Ballistic Missile Defence (BMD) in the rebalance, and the effects this may have on China's nuclear deterrence. This paper seeks to address what effects US ballistic missile defence has on China's nuclear deterrence, and what the repercussions are for regional security in the Asia-Pacific. A policy and doctrinal analysis is used to assess how the US intends to make use of BMD in the Asia-Pacific, and how China is responding to this deployment. The result of this research demonstrates that while current US BMD may not be truly effective at neutralising China's nuclear deterrent, China nonetheless views this development as a potential threat, and is modernising and increasing the capability of its nuclear forces to compensate. The article argues that this has negative implications for security within the Asia-Pacific, by stimulating a security dilemma already evident within the region.

INTRODUCTION.......................................................................... 474

I. THE REBALANCE TO THE ASIA-PACIFIC ........................................... 475

II. US DOCTRINE IN THE ASIA-PACIFIC ............................................... 476

III. CHINA's NuCLEAR AND STRATEGIC DOCTRINE ................................. 481

IV. CHINA's RESPONSES TO US BMD: ............................................... 484

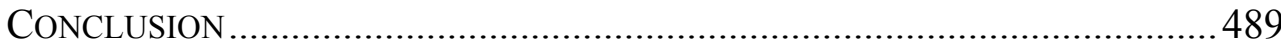

\section{INTRODUCTION}

The rise of China is beginning to have profound repercussions on the nature of security within the Asia-Pacific region. As China's capability continues to grow, the current dominant regional actor, the US, is naturally seeking to maintain pre-eminence through its rebalance to the Asia-Pacific. One of the pivotal aspects of this rebalance is the increasing role of Ballistic Missile Defence (BMD). The concept of BMD is certainly not new. The US and the Soviet Union deployed rudimentary BMD systems in the 1960s, and the US sought to pursue a national missile defence system in the form of the Strategic Defence Initiative in the 1980s. Ultimately, due to a lack of

\footnotetext{
* James Dwyer, Associate Lecturer, BSocSc, BA(Hons), School of Social Sciences, University of Tasmania. Research fields: Nuclear Deterrence, Ballistic Missile Defence, International Security and Strategic Studies.
} 
technological capability and political concerns, these systems never amounted to fully operational assets.

However, in recent years there have been a proliferation of differing BMD systems coming into service with the US and its allies as a result of rapid technological advancements. These systems cover multiple layers of interception, including exoatmospheric interception systems (such as Aegis and GMD), endoatmospheric systems (such as Patriot PAC-3) or even both (in the case of THAAD). What all of these systems have in common is that they are ostensibly intended to provide theatre, as opposed to strategic, defence (with the exception of GMD). While this may well be the case, these systems nonetheless pose a threat to the established strategic deterrence capabilities of states such as China. This paper seeks to address the role that BMD is increasingly playing in the Asia-Pacific through the lense of deterrence theory, the responses China is taking to maintain the credibility of its nuclear deterrent in a BMD environment, and what effects this will have on regional security.

\section{THE REBALANCE TO THE ASIA-PACIFIC}

To contemplate China's responses to US BMD in the Asia-Pacific, and how this in turn will affect regional security, one must first address the US rebalance to the Asia-Pacific, and how BMD is integrated within this rebalance. In a speech at the 2012, Sangri-La Dialogue discussed the shift in doctrine, then Secretary of Defence Panetta revealed plans for the rebalance involving the shift in the disposition of force from a 50/50 split between the Atlantic and Pacific Oceans, to a 40/60 split respectively. ${ }^{1}$ In order to achieve this shift in the disposition of its naval forces, the US intends to station six aircraft carriers in the Pacific, along with the majority of US cruisers, destroyers, SSNs and Littoral Combat Ships by $2020 .^{2}$ Alongside this, US doctrine is shifting from a focus on protracted, low intensity conflicts in the Middle East primarily concentrated on counter-insurgency, to a focus on short, high intensity conflicts in the Asia-Pacific. Given the predominantly maritime operating environment that characterises the AsiaPacific theatre, the US intends to cut the number of its ground forces by approximately 100,000 troops following its withdrawal from Afghanistan. ${ }^{3}$

\footnotetext{
${ }^{1}$ E. Ratner, Rebalancing to Asia with an Insecure China, 36(2) The WASHINGTON QUARTERLy 26 (2013).

${ }^{2}$ R. Cossa and B. Glosserman, Regional Overview: Us Rebalances as Others Squabble, 14(2) COMPARATIVE CONNECTIONS 7 (2012).

${ }^{3}$ S Hawke, Us Military Cuts to Have Minimal Impact in the Asia-Pacific, ABC News, http://www.abc.net.au/pm/content/2014/s3952158.html.
} 
A central aspect of the rebalance is the increasing relevance of BMD and the role that it performs in broader US strategic doctrine. As the rebalance intensifies, more US BMD systems will be deployed within the Asia-Pacific, particularly the naval-based Aegis, but also Patriot and THAAD. As mentioned earlier, these systems are ostensibly intended to provide a layered theatre defence for US and allied forces against attacks originating from rogue states such as North Korea. Alongside the US deployments of BMD, several US allies are either adopting US designed BMD systems (such as Japan with its acquisition of Aegis and PAC-3) or are contemplating the adoption of BMD (as is the case with the Australian Hobart-class destroyer, which will be equipped with the Aegis combat system, and may yet incorporate the Aegis BMD system). ${ }^{4}$ Participants and potential participants in US BMD efforts claim that they do not support national (strategic) BMD efforts. ${ }^{5}$ However, many of the BMD systems deployed by the US and allies, in particular Aegis and THAAD, have demonstrated the potential to engage strategic delivery systems such as Intercontinental Ballistic Missiles (ICBMs), albeit in a limited capacity. Thus, the widespread adoption of BMD within the Asia-Pacific region exacerbates the threat posed by the rebalance to China's strategic capabilities (in particular its nuclear deterrence). China's subsequent responses to this will be analysed in more depth later in this paper.

US strategic policy itself provides evidence that the rebalance is aimed at least partially towards containing China's rising power, for example the shift in military doctrine to a focus on high intensity conflicts in the AsiaPacific. China's military doctrine is similarly undergoing an evolution, particularly in its nuclear posture. The effects of BMD are already affecting the direction China takes in its efforts to modernise its nuclear arsenal and associated strategic delivery systems, all of which will result in decreased regional security within the Asia-Pacific.

\section{US DOCTRINE IN THE ASIA-PACIFIC}

Prior US strategy before the aforementioned shift in focus was centred on the concept of Air Land Battle (ALB), developed in the early 1980s to

\footnotetext{
${ }^{4}$ E. Feege and G. Galdorisi, Australia at the Nexus of 21st Century Power: Keeping Aegis Bmd Options Open, Asia Pacific Defence Reporter, http://www.asiapacificdefencereporter.com/articles/ 230/Air-Warfare-Destroyer. Lockheed Martin Corporation, The Hobart Class Air Warfare Destroyer: Welcome to the Fleet, http://www.lockheedmartin.com.au/content/dam/lockheed/data/ms2/ documents/AWD-HobartClassDestroyer-brochure.pdf.

${ }^{5}$ Australian Government, DEFENCE White PAPER 201382 (ed. Department of Defence, Canberra 2013).
} 
counter Soviet conventional forces in Europe. The central tenet of ALB was the degradation of Soviet rear echelon forces, before they were in a position to engage allied forces. ${ }^{6}$ US air and ground forces were required to be tightly integrated to ensure this could take place (given the predominantly land-based nature of the European theatre). ${ }^{7}$

The primary doctrine that has emerged from the US focus to the AsiaPacific is Air Sea Battle (ASB). As the name suggests, ASB is intended to tightly integrate both air and naval forces under one operational doctrine, in order to revolutionise US war fighting capability in the Asia-Pacific. In contrast to the focus of rear echelon degradation, designed to lessen the adversary's offensive capability as was central to ALB, the purpose of ASB is to minimise or defeat the Anti-Access/Area Denial (A2/AD) capabilities of adversaries. Accomplishing this thus facilitates US force projection capabilities and freedom of movement in the event of a conflict, particularly in the maritime environment that characterises the Asia-Pacific. According to the Air Sea Battle Office, the core problem identified that ASB is required to address is:

Adversary capabilities to deny access and areas to U.S. forces are becoming increasingly advanced and adaptive. These A2/AD capabilities challenge U.S. freedom of action by inducing U.S. forces to operate with higher levels of risk and at greater distance from areas of interest. U.S. forces must maintain freedom of action by shaping the $\mathrm{A} 2 / \mathrm{AD}$ environment to enable concurrent or follow-on operations. $^{2}$

In order to facilitate this, ASB utilises a strategy of D3, standing for disrupt, destroy and defeat. Disrupt is the use of force across all domains (air, land, sea, space and cyberspace) to disrupt adversary Command, Control, Communications, Intelligence, Surveillance and Reconnaissance (C4ISR). Destroy is the traditional (kinetic) warfare involved to destroy adversary $\mathrm{A} 2 / \mathrm{AD}$ infrastructure and associated weapons systems before they can be deployed. Defeat refers to the abilities of US and allied forces to destroy adversary-employed weapons and formations post-deployment, ${ }^{9}$ and it is in this category that BMD plays a key role.

In the event of conflict with China, ASB documents point to the likelihood of there being little to no warning before the onset of hostilities. To achieve this, China would heavily rely on its conventional-tipped

\footnotetext{
${ }^{6}$ D. Skinner, Airland Battle Doctrine, Center for Naval Analyses, 10 (1988).

${ }^{7}$ Air-Sea Battle Office, Air-Sea Battle: Service Collaboration to AdDress Anti-Access \& Area Denial Challenges, 1 (ed. US Department of Defence, United States Military, 2013).

${ }^{8}$ Ibid at 3.

${ }^{9}$ Ibid at 5 .
} 
ballistic missile arsenal to commence conflict, and destroy or debilitate strategic targets and assets before the initiation of broader military operations. ${ }^{10}$ ASB further identifies that targets would not be limited to US military targets and installations, but would also likely include US and allied territories supporting US-led operations, hence the greater interest by many allies for their own BMD systems. While there will be some form of signalling for the purposes of deterrence, in the event of an initiation of conflict, little to no warning inherently suits the perpetrator. Given that ballistic missiles are uniquely suited to this role (the rapid, unpredictable initiation of conflict), BMD is a natural counter to this. As a result, BMD is tightly integrated into ASB, in that systems such as Aegis allow US naval forces greater freedom of movement in hotly contested zones of conflict, for example the South and East China Seas in the event of a conflict with China. BMD in the form of THAAD and PAC-3, in addition to Aegis, will also minimise the impact of pre-emptive ballistic missile attacks on US facilities and strategic assets in the region. Together, these defensive systems will allow the US to enter a conflict sooner and with greater force than would otherwise be the case.

Ultimately, the success of ASB is dependent on a swift and blinding campaign to destroy the opposing forces C4ISR assets, in order to deny the adversary the ability to identify, monitor and assault friendly forces in order to implement their A2/AD strategy. ${ }^{11}$ Thus, the success of ASB hinges on the ability of US forces to rapidly destroy the opposing forces C4ISR and to gain air superiority, in order for naval forces to have sufficient freedom of movement to conduct operations. If this is not achieved, and the opposing forces are able to implement their A2/AD strategy, then ASB will falter. As ASB has yet to be tested in combat, it is difficult to determine whether this strategy will be successful or not, particularly in the case of sophisticated and geographically dispersed C4ISR assets, such as those operated by China. Nonetheless, the US continues to invest in BMD as a component of ASB, specifically to defeat C4ISR. This provides evidence to support the position that US BMD is not just intended to provide defence against rogue states as the US claims, but that these systems are intended to maintain the US' relative power in comparison to China.

The US 2010 Nuclear Posture Review (NPR) provides some additional insight into US thinking regarding China's military modernisation. Specifically, the NPR states that:

\footnotetext{
${ }^{10}$ Ibid at 3 .

${ }^{11}$ R. Haffa and A. Datla, Joint Intelligence, Surveillance, and Reconnaissance in Contested Airspace, 28(3) AIR \& SPACE POWER JOURNAL 37 (2014).
} 
the United States and China's Asian neighbours remain concerned about China's current military modernisation efforts, including its qualitative and quantitative modernisation of its nuclear arsenal. China's nuclear arsenal remains much smaller than the arsenals of Russia and the United States. But the lack of transparency surrounding its nuclear programs-their pace and scope, as well as the strategy and doctrine that guides them-raises questions about China's future strategic intentions. ${ }^{12}$

The uncertainties posed by the ambiguous nature of China's nuclear and strategic posture provide a potent impetus for the US to deploy BMD in the Asia-Pacific. This allows the US to hedge against possible Chinese threats, and provides the US with a significant capability to defeat China's A2/AD assets and strategies. The NPR also highlights a key area of US military doctrine and policy that may increase China's concern regarding the intentions of the US in deploying BMD in the Asia-Pacific. The review states that there are certain contingencies (which are not clearly specified) where the US reserves the right to either escalate to or initiate the use of nuclear weapons in a pre-emptive manner against states not a party to the Nuclear Non-Proliferation Treaty (NPT), or other nuclear armed states (regardless of their status under the NPT) ${ }^{13}$ The report does emphasise that the nuclear option would only be utilised under extreme circumstances, ${ }^{14}$ but the circumstances under which the US would contemplate a "bump" to nuclear are deliberately left unclear.

This is particularly concerning from a Chinese point of view, as was demonstrated at the $8^{\text {th }}$ China-US Dialogue on Strategic Nuclear Dynamics in 2013, where Chinese officials expressed their disappointment and concern that the US still maintained its right to first use of nuclear weapons, and counter-force/launch on (conventional) attack strategies. ${ }^{15}$ The 2013 Dialogue also indicated that China is concerned with US BMD deployments, stating that it is difficult, if not impossible, to determine what constitutes national missile defence systems, and what constitutes theatre defence systems (and thus what threats these systems ultimately pose to China's deterrence). Chinese officials expressed their view that more open and frequent dialogue is needed to address these concerns. ${ }^{16}$ China is already wary of the US nuclear posture, particularly in regards to the US reservation

\footnotetext{
${ }^{12}$ US Department of Defence, NuClear Posture Review Report v (Washington DC2010).

${ }^{13}$ Ibid at viii.

${ }^{14}$ Ibid.

${ }^{15}$ Centre for Strategic and International Studies, 8th China-Us Dialogue on Strategic Nuclear Dyamics: Key Findings and Recommendations, in The Pacific Forum CSIS-China Foundation for International and Strategic Studies 2 (Beijing: Issues and Insights, 2013).

${ }^{16}$ Ibid at 4 .
} 
to pre-emptively use nuclear weapons in certain, unspecified contingencies against other nuclear powers. US BMD only enhances China's suspicion of this situation, as these systems could allow the US to gain a significant nuclear advantage, undermining China's deterrence and increasing the possibility of a US first strike.

The US 2010 Ballistic Missile Defence Review Report also underscores the increasing importance of BMD in US strategic thinking and doctrine. According to the report, the current capabilities of the US BMD systems are too limited to provide a potent enough capability to adequately defend the US and its interests from anything but the most limited of ballistic missile threat scenarios. ${ }^{17}$ In order to provide adequate defence in the face of expanding regional ballistic threats, the US is increasing both its investment in and widening its deployments of BMD assets. It is also developing a space-based tracking system to increase its ability to detect and track ballistic threats, and to provide improved interception vectors and guidance. ${ }^{18}$ This continued investment in capability demonstrates that the US intends BMD to be a more integral component of US forces, something that increases China's uncertainty.

While the 2010 Ballistic Missile Defence Review Report suggests that the main threats the integrated BMD systems are intended to negate are those posed by North Korea and Iran, the report also admits that only Russia and China currently possess sufficient capability to engage in a nuclear assault on the US and its interests. ${ }^{19}$ This can be interpreted as a tacit admission that these systems are also intended to provide some measure of defence against Russian and Chinese nuclear capabilities. Indeed when interviewed about the implications of US BMD for China, USN Admiral Winnefeld, Vice-Chairman of the Joint Chiefs of Staff, stated: "If there are any ancillary effects that China has to consider regarding how that influences their own security, that's for them to judge". ${ }^{20}$ This indicates that the US is aware of how its BMD affects China. However, the US continues to claim that these systems are intended to provide defence against attack from rogue states. As will now be demonstrated, the effects of US BMD are indeed having an acute, negative influence on China's nuclear deterrence, and are thus beginning to affect stability and regional security in the AsiaPacific.

\footnotetext{
${ }^{17}$ US Department of Defence, Ballistic Missile Defence Review Report, iv (2010).

${ }^{18}$ Ibid at v.

${ }^{19}$ Ibid at 4 .

${ }^{20}$ D. Wasserbly and J. Hardy, Us Seeks Closer Bmd Collaboration with Japan, South Korea, IHS JANE's 360 http://www.janes.com/article/38460/us-seeks-closer-bmd-collaboration-with-japan-southkorea.
} 


\section{CHINA’S NUCLEAR AND STRATEGIC DOCTRINE}

In order to discuss how US BMD efforts are affecting regional security within the Asia-Pacific, it is necessary to also discuss China's nuclear and strategic doctrine. The primary objective of Chinese military strategy, as already mentioned in US policy documents, appears to be focused on developing sufficient A2/AD capabilities, intended to deny the US freedom of operation and movement within the first island chain in the event of conflict. ${ }^{21}$ While China cannot match the US' military might, it does not necessarily need to achieve power parity in order to challenge for dominance within its immediate region. China is Asia's dominant land power, and if it sustains its current rate of military spending and economic growth in terms of both GDP and purchasing power parity, and continues to invest in its air and naval forces at current rates, then it will be able to challenge the US on near equal terms inside the first island chain within the medium term. ${ }^{22}$

A report published by the RAND Corporation in 2011 found that conflict between China and the US remains unlikely. However, the use of A2/AD strategies by China, coupled with China's ability to dominate its immediate region (specifically around Taiwan) means that a conflict over Taiwanese reunification may become more likely as China increasingly develops the ability to deny the US access and freedom of movement within the first island chain. ${ }^{23}$ While the issue of the Senkaku/Diaoyu Islands and territorial disputes in the South China Sea have possibly surpassed the Taiwan contingency as the most likely flashpoints for triggering conflict in the Asia-Pacific, the Taiwan issue is nonetheless still a significant threat to regional security. The reunification of Taiwan is a core strategic interest to China, and reunification would serve to further increase China's power within the Asia-Pacific. Thus, this scenario remains relatively dangerous. The report found that in the event of a Sino-US conflict over Taiwan, China's assault on Taiwan would more than likely involve a substantial conventional bombardment of Taiwanese strategic targets, as well as preemptive strikes on US strategic targets and assets within the region, with

\footnotetext{
${ }^{21}$ The first island chain refers to a chain of trans-regional archipelagos that stretch across Eurasia's entire Eastern seaboard. For more information on China's view of the first island chain and its geostrategic importance to China, see T Yoshihara, China's Vision of Its Seascape: The First Island Chain and Chinese Seapower, 4(3) AsIAN POLITICS \& POLICY (2012).

${ }^{22} \mathrm{R}$. Art, The United States and the Rise of China: Implications for the Long Haul, 125(3) POLITICAL SCIENCE QUARTERLY 360 (2010).

${ }^{23}$ J. Dobbins et al., Conflict with China: ProsPeCts, CONSEQUENCES, AND STRATEGIES For DETERRENCE, 2-3 (Santa Monica: RAND Corporation, 2011).
} 
ballistic missiles comprising a large component of these strikes. ${ }^{24}$

One of the leading weapons systems available to China that US BMD particularly seeks to address is the DF-21D Anti-Shipping Ballistic Missile (ASBM). This system is intended to significantly increase the difficulty for the US to access waters within the first island chain, and adds a powerful capability to China's A2/AD strategy. Crucially, the DF-21D would make it difficult for the US to utilise its aircraft carriers in an offensive manner in a cross-strait conflict, considerably decreasing US power projection capabilities within the region. What makes the DF-21D uniquely dangerous to US aircraft carriers is that its range is substantially greater than the range of carrier-based strike aircraft. As a result, a salvo of DF-21Ds can be launched at an aircraft carrier battle group before the battle group is in a position to begin offensive operations. ${ }^{25}$ Notwithstanding Aegis-equipped destroyers and cruisers providing missile defence to a carrier group, a salvo of ASBMs poses a substantial threat to US force projection capabilities. Even a single blow by an ASBM equipped with a conventional warhead would likely render an aircraft carrier or surface combatant inoperable, if not totally destroyed. ${ }^{26}$

The Manoeuvrable Re-entry Vehicle (MaRV) deployed by the DF-21D also poses a substantial problem for BMD systems such as Aegis. While the MaRV is designed to strike a moving target with post-boost phase manoeuvres, it may also be feasible for the Re-entry Vehicle (RV) to take evasive action in the both the midcourse and re-entry phases of flight, in order to confuse and avoid interceptors such as the SM-3 deployed by Aegis-equipped surface combatants. This will inordinately reduce the effectiveness of Aegis and other BMD systems, and decrease the usefulness of the US aircraft carriers, thus reducing US power projection capabilities within the Asia-Pacific.

With regard to nuclear doctrine, China's strategy has remained remarkably stable following its first detonation of a nuclear device in $1964 .^{27}$ Since that time, China has pursued a policy of minimum assured retaliation. China's assured retaliation approach to nuclear deterrence relies

\footnotetext{
${ }^{24}$ Ibid.

${ }^{25}$ The Df-21D is potentially capable of striking US battle groups out as far as the second island chain, well beyond the range of carrier-based aircraft. For more information see E. Sloan, Us-China Military and Security Developments, 66(2) INTERNATIONAL JOURNAL 273-74 (2011).

${ }^{26}$ O. Kreisher, China's Carrier Killer: Threat and Theatrics, THE InTERnATIONAL RELATIONS AND SECURITY NETWORK, available at http://www.isn.ethz.ch/Digital-Library/Articles/Detail/?lng= en\&id=177869.

${ }^{27}$ J. Wirtz, Weapons of Mass Destruction, in CONTEMPORARy SeCurity Studies 273 (A. Collins ed., Oxford: Oxford University Press, 2007).
} 
on small but ambiguous numbers of warheads, as well as opaque deployments of its nuclear forces. Another unique feature of China's nuclear posture is that, in contrast to several other smaller nuclear powers, such as France and Pakistan, ${ }^{28}$ which utilise their nuclear arsenals to deter conventional as well as nuclear attack or coercion, China's nuclear forces are intended (at least according to China) to be solely for the use of deterring nuclear attack or coercion. ${ }^{29}$ This is supported by China's 2008 Defence White Paper, which states that the People's Liberation Army Second Artillery Force (PLASAF), the arm of the PLA responsible for China's strategic rocket forces, is subject to China's no-first-use policy, under which China has pledged to never utilise its nuclear weapons against another state, unless that state has first assaulted China, or China's strategic interests, with nuclear weapons. ${ }^{30}$ PLASAF is also responsible for the maintenance and deployment of China's conventional TBM forces, which, according to the White Paper, will be used for conducting medium and long-range conventional precision strikes against strategic targets in the event of conflict, without the requirement to first ride out an enemy strike before doing so. ${ }^{31}$

China's current no-first-use policy, along with its assured retaliation strategy, is further supported by evidence that China's nuclear warheads are not stored pre-mounted on its ballistic missiles. Rather, the warheads are stored separately, possibly in entirely different facilities to those housing its ballistic missile arsenal. ${ }^{32}$ This particular stance supports China's no-firstuse policy, as well as its policy of assured retaliation, in that it is intended for China to ride out a nuclear strike before retaliating with its own counter strike. China's continued reliance on liquid-fuelled, single warhead armed ICBMs with multi-megaton yields lends further support to China's claims, although China is now moving towards more modern solid-fuelled ICBMs, coupled with smaller yield warheads.

This does not, however, mean that China's nuclear arsenal is exceedingly vulnerable as a result of potentially lengthy launch preparation times. The vast majority of China's ballistic missile arsenal is stored in a large network of hardened tunnels, often referred to as the "underground

\footnotetext{
${ }^{28}$ Which are more comparable to China in terms of the size of their arsenals.

${ }^{29}$ V. Narang, Nuclear Strategy in the Modern Era: Regional Powers AND InTERnational CONFLICT 125 (Princeton: Princeton University Press, 2014).

${ }^{30}$ Information Office of the State Council of the People's Republic of China, China's National DEFENSE IN 200829 (ed. Ministry of National Defence, Beijing 2008).

${ }^{31}$ Ibid.

32 J. Lewis, China's Nuclear Modernisation: Surprise, Restraint, and Uncertainty, in STRATEGIC AsIA 2013-2014: Asia IN THE SeCond Nuclear Age 67 (A Tellis, A Denmark, and T Tanner eds., Washington DC: The National Bureau of Asian Research, 2013).
} 
Great Wall". ${ }^{33}$ This affords China the ability to potentially survive a limited first strike, whilst maintaining sufficient capabilities to retaliate. Regardless, China's reliance on minimum assured deterrence and no-first-use would be greatly challenged by the presence of US BMD within the region.

Indeed, there is evidence to suggest that China may be moving away from its no-first-use doctrine, or that there are certain contingencies that would warrant a nuclear escalation on China's behalf. In 2005, several publications, such as the Financial Times and the Wall Street Journal, quoted Zhu Chenghu, a PLA major general and professor at China's National Defence University as stating: "If the Americans draw (sic) their missiles and position-guided (sic) ammunition on to the target zone on China's territory, I think we will have to respond with nuclear weapons". ${ }^{34}$ While this single comment from a PLA officer does not demonstrate an official Chinese position on the pre-emptive use of nuclear weapons (as the official policy remains one of no-first-use), it nonetheless demonstrates that there are senior figures within the PLA who advocate renouncing the nofirst-use policy, at least against the US. The additional pressures placed on China's nuclear deterrence and security as a result of US BMD will only enhance the position of those who advocate renouncing the no-first-use policy.

\section{CHINA’S RESPONSES TO US BMD:}

Given its current doctrine and force disposition premised on a small and relatively unsophisticated nuclear arsenal, China is in a poor position to continue relying on its nuclear deterrence in the face of US BMD. Of particular concern is the capability and flexibility of the sea-based Aegis BMD system. As stated earlier, Aegis is officially designed to intercept TBMs in the exoatmospheric midcourse stage of flight. However, in the event of conflict with China, Aegis-equipped warships would possibly be able to sail in close proximity to the Chinese coastline, particularly if the ASB doctrine allows the US to gain air and naval superiority. If so, these vessels would be able to intercept both TBMs and ICBMs in the vulnerable boost stage of flight immediately after launch, thus posing a substantial threat to China's nuclear deterrence. Indeed, this specific scenario has been outlined as a particular concern to Chinese strategists. For example, Ji Yanli of the Beijing Aerospace Long March Scientific and Technical Information

\footnotetext{
${ }^{33}$ Ibid at 78.

${ }^{34}$ K. Cooney, Chinese-American Hegemonic Competition, in THE RISE OF CHINA AND INTERNATIONAL SECURITY: AmERICA AND Asia ReSPOND 44 (K. Cooney and Y. Sato eds., London: Routledge, 2009).
} 
Institute has stated:

If such [sea-based BMD] systems begin deployment in areas such as Japan or Taiwan, the effectiveness of China's strategic power and theatre ballisticmissile capabilities would weaken tremendously, severely threatening national security. ${ }^{35}$

Similarly, Dai Yanli has cautioned: "Clearly, if Aegis systems are successfully deployed around China's periphery, then there is the possibility that China's ballistic missiles would be destroyed above their launch points" ${ }^{36}$ Furthermore, the high burnout rate of the SM-3 interceptor allows Aegis to engage objects in LEO, as was demonstrated in 2008 during Operation Burnt Frost, where Aegis was used to destroy a malfunctioning US satellite. ${ }^{37}$ This capability, coupled with the close proximity of Aegisequipped surface combatants, may well afford the US the ability to neutralise Chinese ICBMs in any phase of flight, while threatening China's space-based assets at the same time. ${ }^{38}$ Ultimately, this demonstrates that China is very concerned by the capabilities of the Aegis BMD system, and that even if Aegis is officially incapable of engaging ICBMs, it nonetheless poses a significant threat to China's nuclear deterrence.

There are several advancements that China can apply to modernise its nuclear arsenal, in order to defeat or minimise the threat of current US BMD. One of the most effective technologies that could be utilised (which China does not currently deploy) is Multiple Independently Targetable Re-entry Vehicle (MIRV) technology. MIRVs are more effective versions of the earlier Multiple Re-entry Vehicle (MRV) design, allowing a single ballistic missile to carry and deploy several RVs, each of which is capable of engaging a separate target. ${ }^{39}$ The US Department of Defence (DOD) has affirmed that China may have possessed the capability to manufacture both MRV and MIRV technology for at least 20 years, but has never actually deployed such systems. ${ }^{40}$ MIRVs pose a substantial challenge to the success

\footnotetext{
${ }^{35}$ Ji Yanli and T. Yoshihara, Japanese Bases and Chinese Missiles, in REBALANCING U.S. ForCEs: BASING AND Forward PRESENCE IN THE ASIA-PACIFIC 47 (C. Lord and A. Erickson eds., Annapolis: Naval Institute Press, 2014).

${ }^{36}$ Ibid.

${ }^{37}$ Missile Defence Agency, Aegis Ballistic Missile Defence One-Time Mission: Operation BuRnT Frost, (US Department of Defence, 2014).

${ }^{38}$ G. Moore, An International Relations Perspective on the Science, Politics, and Potential of an Extraterrestrial Sino-Us Arms Race, 35 AsIAN PERSPECTIVE 651 (2011).

${ }^{39}$ B. Garrett And J. Hart, The A to Z of Nuclear, Biological and Chemical Warfare 143 (Maryland: Scarecrow Press, Inc., 2009).

${ }^{40}$ Office of the Secretary of Defence, ANNuAl Report to Congress: Military and Security Developments Involving the People's Republic of China 201030 (ed. US Department of Defence Washington DC 2010).
} 
of BMD in the event of an exchange, as every incoming ballistic missile has the potential to deploy several warheads, each on a different trajectory. Thus, the difficulty involved in tracking and intercepting incoming warheads is exponentially increased. MIRVs necessitate more accurate delivery systems than those equipped to single warhead-carrying systems, as the MIRV warheads are required to be smaller and lighter, in order to fit several into the same space that a single warhead usually occupies. Therefore, this results in smaller explosive yields per warhead. ${ }^{41}$ However, MIRVs are also capable of striking a single target with several warheads at once, in the manner of earlier MRVs, so overall there is no loss of total destructive potential per ICBM. ${ }^{42}$

MIRVs would be particularly effective in boosting the credibility of China's nuclear deterrence, for several reasons. Firstly, as mentioned above, MIRVs reduce the effectiveness of BMD, by exponentially increasing the difficulty in achieving a successful negation of an incoming ballistic missile assault. This dramatically increases the costs of defence, thus shifting the advantage back to the offence (as with traditional nuclear balances). ${ }^{43}$ MIRVs also increase the credibility of a nuclear deterrent, by increasing the survivability of a state's nuclear arsenal. For example, if $50 \%$ of a state's ICBMs are destroyed in a pre-emptive strike, then that state can now attack $50 \%$ fewer targets in retaliation (as it has lost half of its nuclear arsenal). However, if this same scenario occurred against a state that has "MIRVed" a significant portion of its ICBM arsenal, then the loss of 50\% of its strategic delivery systems is not as significant an impact on its ability to retaliate. This is due to the multiple, independently targetable warheads that are deployed by individual ICBMs, which allow the attacked state to still engage multiple targets in retaliation, although perhaps with less total megatonnage than was originally allocated per target. The enormous destructive potential of nuclear weapons results in this being a relative non-issue, however, as even a low-yield warhead will still result in destruction well beyond what is capable with conventional warheads.

The US Department of Defence 2015 Annual Report to Congress on China for the first time indicated that China has deployed MIRVs on some of its DF-5 arsenal. This move by China marks a dramatic shift in focus away from its minimum assured retaliation posture, and indicates that China

\footnotetext{
${ }^{41}$ Narang, Nuclear Strategy in the Modern Era: Regional Powers and International Conflict 135.

${ }^{42}$ L. Freedman, The Evolution of Nuclear Strategy 336 (New York: Palgrave Macmillan, 2003).

${ }^{43}$ It should be noted that BMD does not necessarily shift the advantage to the defence, even if it does increase the capabilities of defence in comparison to the offence. However, the deployment of MIRVs will shift the advantage firmly back to the offence.
} 
is seeking to overcome the threat posed by US BMD in the Asia-Pacific. Indeed the 2015 Report to Congress acknowledges this very issue, stating:

A new generation of mobile missiles, with warheads consisting of MIRVs and penetration aids, are intended to ensure the viability of China's strategic deterrent in the face of continued advances in U.S. and, to a lesser extent, Russian strategic ISR, precision strike, and missile defence capabilities. ${ }^{44}$

This provides clear evidence that US BMD is directly influencing China to alter its nuclear doctrine and modernise its nuclear arsenal, in order to maintain the credibility of its nuclear deterrent.

China has also been pursuing the development of a larger, more capable ICBM than its current ICBM fleet, under the designation DF- 41 . $^{45}$ The DF-41 has had a tumultuous development period, undergoing several apparent cancelations and restarts of the program. Much of the information regarding the DF-41 is shrouded in secrecy. According to the Missile Threat Project, development of the DF-41 began as early as 1986, in an effort to replace the earlier DF-5 with a more modern and capable design. ${ }^{46}$ Several reports later concluded that the development of the DF-41 was cancelled around the year 2000, presumably due to the development of the cheaper DF-31A. However, more evidence has recently surfaced indicating that development of the DF-41 was merely postponed, rather than cancelled. In its annual report to congress in 2013, the US DOD stated that the PLASAF was developing a new generation of road mobile ICBM that was capable of deploying MIRVs, but did not state the designation of the ICBM in question. $^{47}$

Furthermore, an accidental release by a CCP environmental monitoring agency appears to confirm the existence of the DF-41. ${ }^{48}$ In August 2014, The Global Times published information found in a CCP environmental monitoring file that inadvertently confirmed the existence of the DF-41 ICBM, and that the missile possesses MIRV capability. ${ }^{49}$ The revelation

\footnotetext{
${ }^{44}$ Office of the Secretary of Defence, AnNuAL Report to CONGRESS: Military Power of THE PeOPle's RePublic of ChINA 201531 (ed. US Department of Defence 2015).

${ }^{45}$ China's current ICBMs include the silo-based DF-5 liquid-fuelled ICBM, and the DF-31/DF-31A road mobile, solid-fuelled ICBMs, all of which are currently believed to be armed with single warheads.

${ }^{46}$ Missile Threat Project, $D f-41$ (Css- $\left.X-10\right)$, George C. Marshall and Claremont Institutes, http://missilethreat.com/missiles/df-41-css-x-10/?country=china\#china.

${ }^{47}$ Office of the Secretary of Defence, ANNuAL Report to Congress: Military AND SECURITY DeVelopments InVolving the People's Republic of China 20136 (ed. US Department of Defense, Office of the Secretary of Defense Annual Report to Congress 2013).

${ }^{48}$ N. Dandan, New Generation of Icbms' Revealed by an Accidental Slip, The Global Times, http://www.globaltimes.cn/content/873862.shtml.

${ }^{49}$ Ibid.
} 
appears to be unintentional, with the agency responsible quickly withdrawing the file from public view. Song Zhongping, a Chinese defence analyst, argues that China's main motivation for developing the DF-41 and its associated MIRV capabilities is primarily to respond to the negative effects of US BMD on its own security. Zhongping states that the DF-41 is specifically designed to have quicker response times and much more advanced penetration capabilities, as "only with these advantages can they have the chance to quickly penetrate through the missile defence system of the US." ${ }^{50}$ Tang Bohu, a military commentator with Ifeng News, points out that the revelation of the existence of the DF-41 and its MIRV capability appears to be truly accidental, stating that "I believe revealing the information was unintentional. But sooner or later, China will demonstrate these new nuclear weapons at international military parades. Eventually, the weapons will be meant for deterrence". ${ }^{51}$ The revelation of the existence of the DF-41 and its MIRV capability (development of which was until now presumed to be cancelled or mothballed) further demonstrates that China is seeking the capability to defeat US BMD in the event of conflict.

China could also accelerate the deployment of newer Ballistic Missile Submarines (SSBNs) and Submarine Launched Ballistic Missiles (SLBMs), which would provide increased survivability for a portion of China's nuclear arsenal. These systems, particularly if equipped with MIRVs, would significantly erode the effectiveness of current US BMD systems. An SSBN could approach close to hostile shores undetected and launch its SLBMs on a depressed trajectory shot, ${ }^{52}$ which would give very little warning for BMD assets to acquire the incoming missiles, track their trajectory and deploy interceptors to negate the threat.

Additionally, China could develop more advanced penetration aids for its ICBM arsenal, such as flares, chaff and decoys. China no doubt deploys various penetration aids already, but as more information becomes public regarding US BMD, China may be able to tailor its penetration aids to specifically defeat these systems. Moreover, it is unlikely that US BMD systems would have the technological capability in the short to medium term to be able to discriminate between penetration aids and RVs carrying live warheads. ${ }^{53}$ Furthermore, penetration aids are relatively cheap and simple to implement, making this strategy particularly appealing to China.

\footnotetext{
${ }^{50}$ Ibid.

${ }^{51}$ Ibid.

${ }^{52}$ L. Gronlund and D. Wright, Depressed Trajectory Slbms: A Technical Evaluation and Arms Control Possibilities, 3(1) SCIENCE AND Global SECURITY 101 (1992).

${ }^{53}$ L. Bin, Z. Baogen, and L. Zhiwei, China Will Have to Respond, 57(6) Bulletin of AtomiC SCIENTISTS 28 (2001).
} 
Thus, China is presented with two options. Firstly, China could simply maintain the status quo, and accept that the effectiveness and credibility of its nuclear deterrence against the US has been diminished. To a casual observer, this approach should be unproblematic, as China should have nothing to fear from the US as a status quo actor, providing China conforms to international norms and law. However, states inherently fear one another, given they possess the capacity to inflict harm upon each other, coupled with their inability to truly ascertain the intentions of other states. This will only be enhanced if one possesses a substantial advantage over the other. If the US can limit China's ability to defend itself, by reducing the effectiveness and credibility of its nuclear deterrent, then China will have more to fear from the US. This issue is enhanced by the ambiguous nature of US nuclear doctrine; Wherein the US reserves the right to initiate a nuclear conflict against another nuclear power under certain scenarios, but does not specify what these scenarios are. ${ }^{54}$ Therefore, the uncertainty posed by US nuclear doctrine, coupled with the US BMD deployed in the AsiaPacific, means that China will not simply accept the status quo, due to the implications of nuclear deterrence being undermined, which then stimulates a security dilemma within the region.

China's second option is to modernise its nuclear arsenal, and increase the amount of active warheads and associated delivery systems it has in service, as well as adopting more technologically sophisticated means of warhead delivery, such as MIRVs and penetration aids. Indeed, there is abundant evidence to suggest that this is the course of action that China is adopting. The revelations in August 2014 confirming the existence of the DF-41 and its MIRV capability, and the US confirmation of MIRVequipped DF-5's in May 2015 both demonstrate that US BMD is negatively affecting China's nuclear deterrent, and China is taking steps to negate this threat. Thus, the US and China are engaging in an offensive/defensive arms race that will only serve to decrease regional security in the Asia-Pacific.

\section{CONCLUSION}

The motivations behind the US deployment of BMD, and China's subsequent responses to these systems, are easy to understand. For the US, BMD provides (superficially) an increased ability to defend both itself and its interests, thus allowing it to maintain the status quo as the dominant regional actor in the Asia-Pacific. The publically declared purpose of the US $\mathrm{BMD}$ in the Asia-Pacific, to provide defence against a ballistic missile

\footnotetext{
${ }^{54}$ US Department of Defence, NuClear PostuRe ReVIEW REPORT, at v.
} 
attack from North Korea, ${ }^{55}$ may well be the primary motivator for the US to deploy such systems. However, these systems will of course be used to the full extent of their capabilities in the unlikely event of a conflict with China. Therefore, China naturally views these systems as the threat that they are (even if the US truly does not intend them to threaten China's deterrence capabilities) and will escalate its military modernisation program in order to defeat US BMD.

Unfortunately, the US will view China's modernisation and the buildup of its strategic forces as a potential threat, and will thus increase its deployment of BMD in kind. This is also a logical conclusion on the part of the US, due to the opacity of China's intentions within the region. As great powers seek to maximise their relative power, the US will interpret China's defensive build-up as potentially offensive in nature, and thus seek to correct the manifestation of security in the region to what it views as the appropriate balance.

However, this in turn will be interpreted by China as potentially offensive, which is further emphasised by the ambiguous nature of BMD. China will thus seek to further increase its nuclear and ballistic capabilities in order to correct the balance of power to what it sees as appropriate (in other words, to maximise its power relative to the US). Thus, the effects of US BMD on China's nuclear deterrence serve to further fuel the security dilemma that is already evident in the Asia-Pacific, as a result of the nature of great power interactions.

Ultimately, this results in US BMD reducing security in the AsiaPacific, rather than increasing security as was intended by the US, due to the potentially offensive aspects of BMD posing a threat to China (whether this was intended or not), forcing China to increase its capabilities to ensure its security. In order to do so, the actions that China is forced to take will appear to be offensive in nature, confirming to the US that China has hostile intentions, forcing the US to respond in kind. As one can therefore conclude, US BMD reduces regional security in the Asia-Pacific, by further exacerbating an existing security dilemma through the erosion of China's nuclear deterrence capabilities.

\footnotetext{
${ }^{55}$ BAllistic Missile Defence ReView Report, at 4.
} 